DE

M E D I C I N A

T R O P I C A L

$\mathrm{DE}$

SÃO PAULO

JOURNAL OF THE SÃO PAULO INSTITUTE OF TROPICAL MEDICINE

'Universidade Federal do Piauí, Campus Ministro Reis Velloso, Parnaíba, Piauí, Brazil

2Universidade Federal de Minas Gerais, Instituto de Ciências Biológicas, Belo Horizonte, Minas Gerais, Brazil

${ }^{3}$ Fundação Oswaldo Cruz, Centro de Pesquisas René Rachou, Belo Horizonte, Minas Gerais, Brazil

Correspondence to: Gustavo Portela Ferreira Universidade Federal do Piauí, Campus Ministro Reis Velloso, Av. São Sebastião, 2819, CEP 64202-020, Parnaíba, PI, Brazil Tel: +55 $86999203470,+558633235846$

E-mail: gtvpf@ufpi.edu.br

Received: 29 March 2019

Accepted: 9 September 2019

\section{Circulation of Chikungunya virus East-Central-South Africa genotype during an outbreak in 2016-17 in Piaui State, Northeast Brazil}

Felipe Daniel Cardoso ${ }^{(\mathbb{1} 1}$, Izabela Mauricio de Rezende ${ }^{\left({ }^{\circ} 2\right.}$, Emanuela Lima Teixeira Barros ${ }^{(1)}$, Lívia Sacchetto ${ }^{\circledR 2}$, Tereza Cristina de Carvalho Souza Garcês ${ }^{\circledR 1}$, Natalia Ingrid Oliveira Silva ${ }^{\circledR}$, Pedro Augusto Alves ${ }^{\left({ }^{1}\right.}$, Jefferson Oliveira Soares ${ }^{(1)}$, Erna Geessien Kroon ${ }^{(12}$, Anna Carolina Toledo da Cunha Pereira ${ }^{\circledR}$, Betânia Paiva Drumond ${ }^{\circledR 2}$, Gustavo Portela Ferreira ${ }^{\circledR 1}$

\section{ABSTRACT}

Chikungunya virus (CHIKV) is an arbovirus that emerged in the Americas in 2013. Infection with CHIKV is symptomatic in most of the cases and patients can develop chronic arthralgia that lasts from months to years in over $40 \%$ of the cases. The East-Central-South Africa (ECSA) genotype was introduced in Brazil in 2014, in Bahia State. Here we report the circulation of the CHIKV ECSA genotype in Piaui State, Northeast Brazil, during the years 2016-2017. The phylogenetic analysis revealed a single introduction of this lineage probably in 2015 and its maintenance at least until 2017. This analysis has also demonstrated the proximity of this genotype with isolates from neighboring States, and its partial nucleotide sequence of the viral E1 gene revealed a synapomorphy synonyms. This finding highlights the spread of the ECSA genotype in Brazil and supports its circulation in the Brazilian Northeast.

KEYWORDS: Chikungunya virus. Brazil. ECSA genotype. Arbovirus. Togavirus. Alphavirus. Molecular surveillance. Epidemiology. E1 gene.

\section{INTRODUCTION}

Chikungunya virus (CHIKV) is an arthropod-borne, enveloped, positive singlestranded RNA virus of the family Togaviridae, genus Alphavirus. Its genome contains two open reading frames encoding four nonstructural (nsP1-4) and five structural proteins (C, E3, E2, 6K, E1) ${ }^{1,2}$. Studies performed in Thailand, Malaysia, Mayotte and La Reunion islands have shown that 52 to $98 \%$ of the infected patients develop symptoms that range from fever, headache, myalgia, articular edema and rash to intense polyarthralgia and severe joint pain ${ }^{3-6}$. Furthermore, a variety of studies have reported a high prevalence of chronic arthralgia, which can last from months to years in approximately $40 \%$ of the infected people $\mathrm{e}^{7,8}$.

CHIKV was isolated for the first time in 1952-53 in Tanzania ${ }^{9}$. So far, four distinct lineages have been recognized: East-Central-South Africa (ECSA), Indian Ocean (IOL), Asian and West African lineages ${ }^{10}$. Until 2004, CHIKV had caused small and sporadic outbreaks at the African and Asian continents, however that year, the ECSA genotype caused massive outbreaks in the East Africa coast ${ }^{11,12}$. This was followed by unprecedent epidemics in Indian Ocean islands and Asia as well as the first outbreak in a temperate region in Italy $^{13}$. In 2013, the first cases of 
autochthonous transmission in the Americas were reported in the Caribbean island of Saint Martin, caused by the Asian genotype ${ }^{14}$. In late 2014, the Asian genotype was detected in the Amapa State, Northern Brazil ${ }^{15}$, whereas the ECSA genotype was later detected in Bahia State, Northeast Brazi ${ }^{16}$. According to the Brazilian Ministry of Health, between 2016 and 2018, 547,797 suggestive cases of CHIKV were reported in the country, with 361,640 laboratory confirmed cases and $387 \mathrm{CHIKV}$-associated death $\mathrm{s}^{17-19}$. The Northeast region of the country accounted for $86.4 \%$ and $76,8 \%$ of the suggestive cases during 2016 and 2017, respectively ${ }^{17,19}$.

Piaui State (PI) is located in the Northeast region of Brazil, and borders the States of Bahia, Ceara, Pernambuco and Maranhao and Tocantins (Figure 1). Until 2016, no cases of CHIKV (imported or autochthonous) were reported in Piaui State. However, in 2016, the incidence rate of suggestive CHIKV infections increased to 86.4 per 100.000 inhabitants, the lowest in the Northeast region ${ }^{19}$, and peaked in 2017 reaching 194.5 per 100.000 inhabitants $^{17}$. In 2018, the incidence rate dropped to 17.4 per 100.000 inhabitants. In addition, deaths caused by CHIKV infection have been confirmed in Piaui State in 2016 and 2017 $7^{17,18}$. Considering that there has been an increase in the incidence rate of CHIKV in Piaui State, the aim of the present study was to investigate and to identify the circulating genotype in the State.

\section{MATERIALS AND METHODS}

\section{Clinical samples and ethical statement}

From April 2016 to November 2017, clinical samples were collected at the Urgency Medical Service Unity and State Hospital Dirceu Arcoverde in the city of Parnaiba, Piaui State, Brazil. Serum were obtained from whole blood samples collected from patients presenting two or more of the following symptoms: fever $\left(>38.5^{\circ} \mathrm{C}\right)$, headache, arthralgia, myalgia, rash and/or hemorrhagic manifestations. Informed consent was obtained from all the patients or their legal guardians, and a form with questions about age, days of symptoms, travel history and previous diagnostics was filled out. The collected samples were stored at $4{ }^{\circ} \mathrm{C}$, transported to the research laboratory at the Federal University of Piaui within $5 \mathrm{~h}$ after collection and stored at $-70^{\circ} \mathrm{C}$. When available, results of the serological tests for DENV and CHIKV performed by public health services were retrieved. The research was approved by the Human and Ethics Committee of the Federal University of Piaui, under the protocol $\mathrm{N}^{\circ}$ CAAE 46111615.0.0000.5214.

\section{Molecular investigation of Chikungunya infection}

Viral RNA extractions were performed from serum of patients presenting three or more symptoms, less than

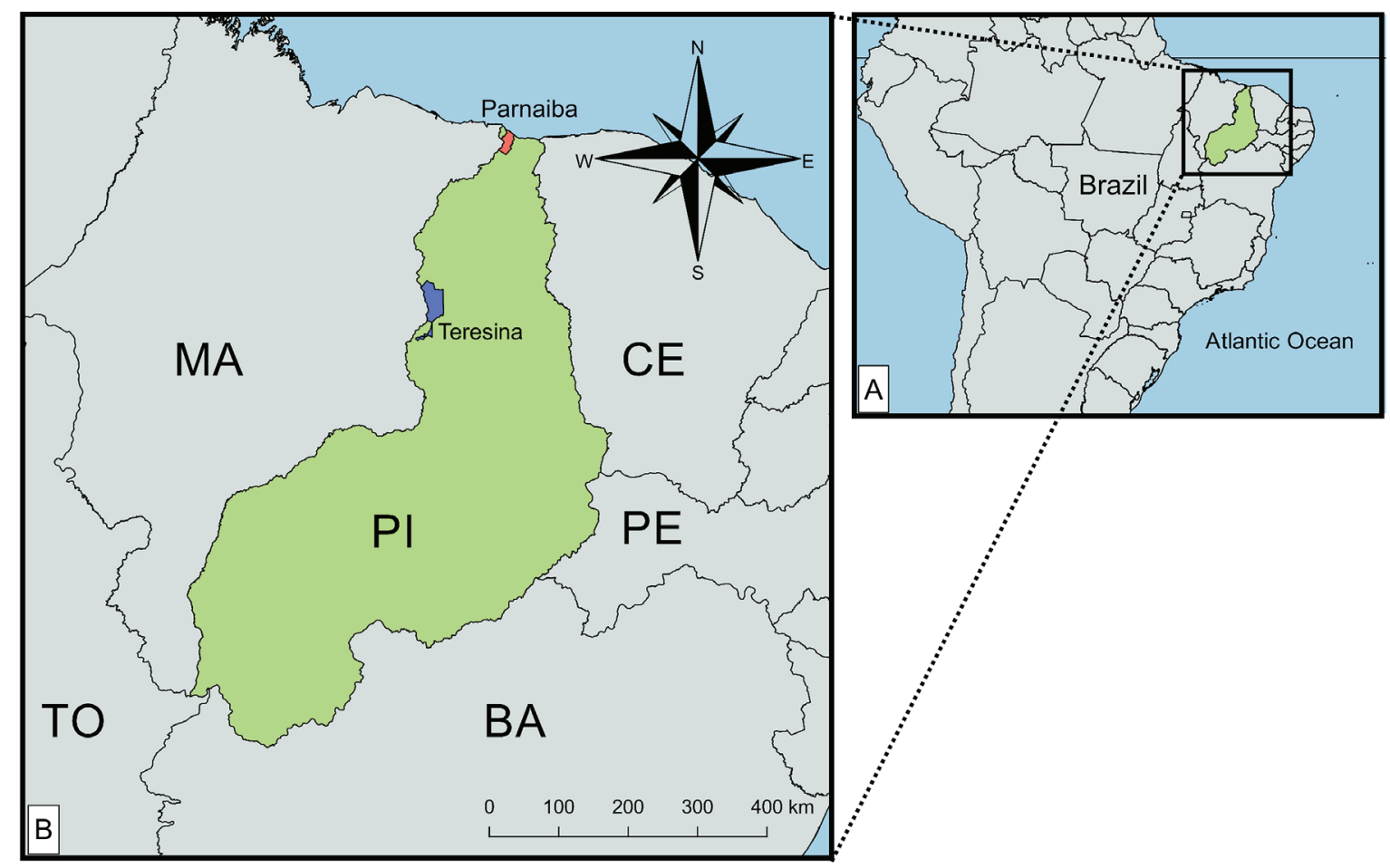

Figure 1 - The geographic location of Piaui State in Brazil. Teresina and Parnaiba municipalities are highlighted in blue and orange, respectively. BA: Bahia; CE: Ceara; MA: Maranhao; PE: Pernambuco; PI: Piaui TO: Tocantins. 
5 days of the onset of symptoms and the presence of IgM antibodies against CHIKV, when available. The viral RNA extraction was perfomed using QIAamp viral RNA Mini Kit (Qiagen, Hilden, Germany) or NucleoSpin ${ }^{\circledR}$ RNA Virus (Macherey-Nagel, Düren, Germany), following the manufacturer's instructions.

The cDNA synthesis was carried with random hexamers (20 $\mu \mathrm{M}$, Qiagen, Hilden, Germany) and Moloney Murine Leukemia virus reverse transcriptase (Promega, Madison, Wisconsin, USA), following the manufacturer's instructions. Using specific primers previously described for CHIKV E1 (DVRChk-F 5' ACCGGCGTCTACCCATT CATGT 3'; DVRChk-R 5' GGGCGGGTAGTCCATGTTGTAGA 3' $)^{20}$ and CHIKV E2 (JM1 5' GCAGACGCAGAGAGGGCCAG 3'; JM2 5' CGTGCTGCAAGGTAGTTCTC 3'; JM3 5' GCTATTTGTAAGAACGTCAG 3'; JM4 5'TACCGTGCTGCGGTCGGGA A 3' ${ }^{21}$ genes, partial genome sequences were amplified. The expected products of $330 \mathrm{bp}(E 1)$ and $240 \mathrm{bp}(E 2)$ were separated by electrophoresis in $1.5 \%$ agarose gels stained with the intercalant agent GelRed ${ }^{\mathrm{TM}}$ (Biotium Inc., Freemont, California, USA) and visualized under U.V. lights. The expected bands were excised from the gel and purified using the QIAQuick Gel Extraction Kit (Qiagen, Hilden, Germany) for nucleotide sequencing.

\section{Nucleotide sequencing and phylogenetic analysis}

PCR amplicons of the $E 1$ and $E 2$ genes were sequenced using $0.5 \mathrm{uM}$ of each specific primer (forward and reverse) and approximately $10 \mathrm{ng}$ of each DNA sample. The sequencing was performed in a ABI 3130 DNA Analyzer (Applied Biosystems) using BigDye Terminator v3.1 Cycle Sequencing Kit (Applied Biosystems), using the Sanger sequencing platform of Rene Rachou Institute (Fiocruz, Minas Gerais, Brazil). Raw data were analyzed and final contigs were assembled using the Geneious R9 version 9.1.8 $8^{22}$. The partial sequences of $E 2$ and $E 1$ genes were concatenated in frame and aligned to 74 concatenated sequences of CHIKV genotypes retrieved from GenBank (http://www.ncbi.nlm.nih.gov) using CLUSTALW, implemented on MEGA6 ${ }^{23}$. The nucleotide substitution model of Kimura 2-parameters with Gamma distribution (4 categories) $(\mathrm{K} 2+\mathrm{G})$ was selected using jModelTest v 2.1.4 ${ }^{24}$. The maximum likelihood tree was reconstructed using MEGA $6^{23}$ with a total of 88 sequences, the nucleotide substitution model $\mathrm{K} 2+\mathrm{G}$ with 1000 bootstrap replicates.

Bayesian inferences were performed using BEAST package 1.8.4 ${ }^{25}$ with Markov Chain Monte Carlo algorithms (MCMC). Input files for BEAST v.1.8.4 were created with BEAUTi v.1.8.4 ${ }^{26}$, using 88 concatenated E2E1 sequences.
The best model was selected comparing the marginal likelihood estimations (MLE) ${ }^{27}$. The estimates were performed using the nucleotide substitution model GTR, with gamma distribution (four categories), under the relaxed molecular clock and the Bayesian skyline demographic Model. Three hundred million chains were run, the first 30 million steps were discarded, and convergence of parameters was verified with Tracer v.1.5.028. The trees were sampled at every 10,000 steps and then summarized in a maximum clade credibility tree using TreeAnnotator v.1.8. $2^{29}$. The final tree was visualized in FigTree v.1.4.3 ${ }^{30}$.

\section{RESULTS}

\section{Clinical samples and serological results}

During April/2016 and November/2017, 580 patient samples were collected. $40.2 \%$ (233/580) of samples were collected during 2016, whereas 59.8\% (347/580) were collected during 2017. The majority of the patients were woman $(66.4 \%)$. The main clinical signs were fever $(84.65 \%)$, arthralgia $(82.06 \%)$, headache $(77.75 \%)$ and myalgia (71.38\%) (Table 1). However, $0.86 \%$ (5/580) of patients have also presented neurological complications, such as encephalitis. Of the 580 samples collected, serological tests for CHIKV IgM were performed on $52.59 \%(305 / 580)$ samples, CHIKV IgG on $19.31 \%$ (112/580), DENV IgM on 75.69\% (439/580) and DENV $\mathrm{IgG}$ on $61.72 \%$ (358/580). Of these, $70.16 \%$ (214/305) were positive for CHIKV IgM, $14.12 \%$ (62/439) for DENV IgM and $36(6.21 \%)$ were positive for both CHIKV and DENV IgM tests (Figure 2).

\section{RT-PCR for CHIKV}

From the total of collected samples, RNA extraction were performed on $19.31 \%$ (112/580) samples. Of these, $56.25 \%$ (63/112) were from 2016 and $43.75 \%$ (49/112) from 2017. Of the analyzed samples, $29.46 \%$ (33/112) were positive for CHIKV by PCR, with $57.58 \%$ (19/33) from 2016 and $42.42 \%$ (14/33) from 2017. Of the positive samples, CHIKV specific IgM tests were available for $36.36 \%$ (12/33) patients, of which 50\% (6/12) were CHIKV IgM positive (Figure 2). 87.88\% (29/33) of the PCRpositive CHIKV samples had DENV IgM tests performed, and $10.34 \%(3 / 29)$ of samples were positive. Only one of the CHIKV-positive samples with serological tests results presented both DENV and CHIKV IgM antibodies. Of the 33 CHIKV-positive samples, one (3.03\%) patient of 11 years old presented clinical signs of encephalitis as well as fever, vomiting, headache, myalgia and eye 
Table 1 - Demographic and clinical characteristics of suspected cases of CHIKV infection during April/2016 to November/2017 in Piaui, Brazil, according to CHIKV laboratory test results (RT-PCR).

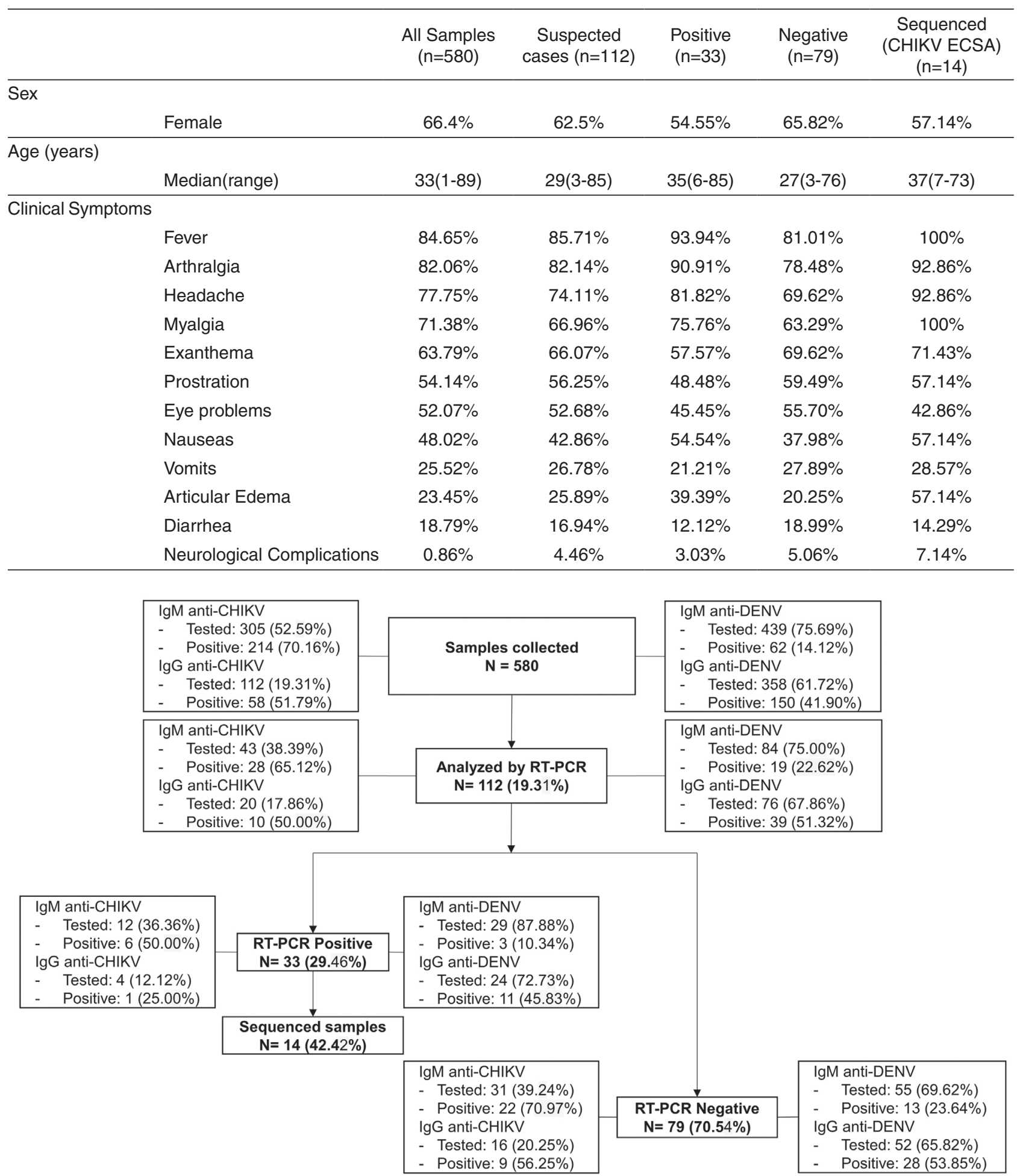

Figure 2 - Flowchart showing the total number of patient samples collected and laboratory tested (RT-PCR) to CHIKV during April/2016 to November/2017.

complications. The presence of CHIKV IgM antibodies was detected in this sample, but DENV IgM and IgG were not detected. Among the PCR negative samples (79/112),
CHIKV IgM tests were performed on $39.34 \%$ (31/79) of the patients. Of these, $70.97 \%$ (22/31) of the samples presented CHIKV IgM antibodies (Figure 2). 


\section{Nucleotide sequencing and phylogenetic analysis}

The partial sequence of $E 2$ and $E 1$ genes of 14 samples from 2016 and 2017 were determined (GenBank accession $\mathrm{N}^{\circ}$ MK510154-MK510181). The partial sequences of E2 (208 nt) and El (120 nt) genes were concatenated in frame (328 nt; corresponding to positions 8,804 to 8,923 and 10,253 to 10,460 compared to the nucleotide sequence of CHIKV strain BHI3745/H804709, isolated in Feira de Santana, Bahia (GenBank accession $N^{\circ}$ KP164570). The phylogenetic analysis based on the Maximum likelihood (Supplemental Figure 1) and Bayesian methods revealed that all sequenced isolates belonged to the ECSA genotype and clustered together, forming a monophyletic group, called CHIKV/PI/2016-2017 (supported by a posterior probability (PP) equal to 0.96 ). This group clustered with other CHIKV isolates, circulating from 2014 to 2016, in Bahia $^{16}$, Rio de Janeiro ${ }^{31}$, Sergipe ${ }^{32}$, Alagoas ${ }^{33}$, Paraiba and Pernambuco ( $\mathrm{PP}=1)$ (Figure 3).

The isolates from CHIKV/PI/2016-2017 had the most recent common ancestor (MRCA) estimated in 2015 (95\% Bayesian credible interval $=2014$ to 2016). The nucleotide sequences within CHIKV/PI/2016-2017 were identical to each other. When sequences within CHIKV/PI/2016-2017 were compared to sequences from other Brazilian isolates (collected during 2014-2016), a nucleotide similarity of $99.3 \%$ was observed. Analysis of nucleotide and predicted amino acid sequences of CHIKV/PI/2016-2017 compared to sequences belonging to others Brazilian CHIKV/ ECSA genotypes, indicated a synonymous nt substitution characterized as synapomorphy (position 87 of the E1 gene of CHIKV/PI/2016-2017 sequences).

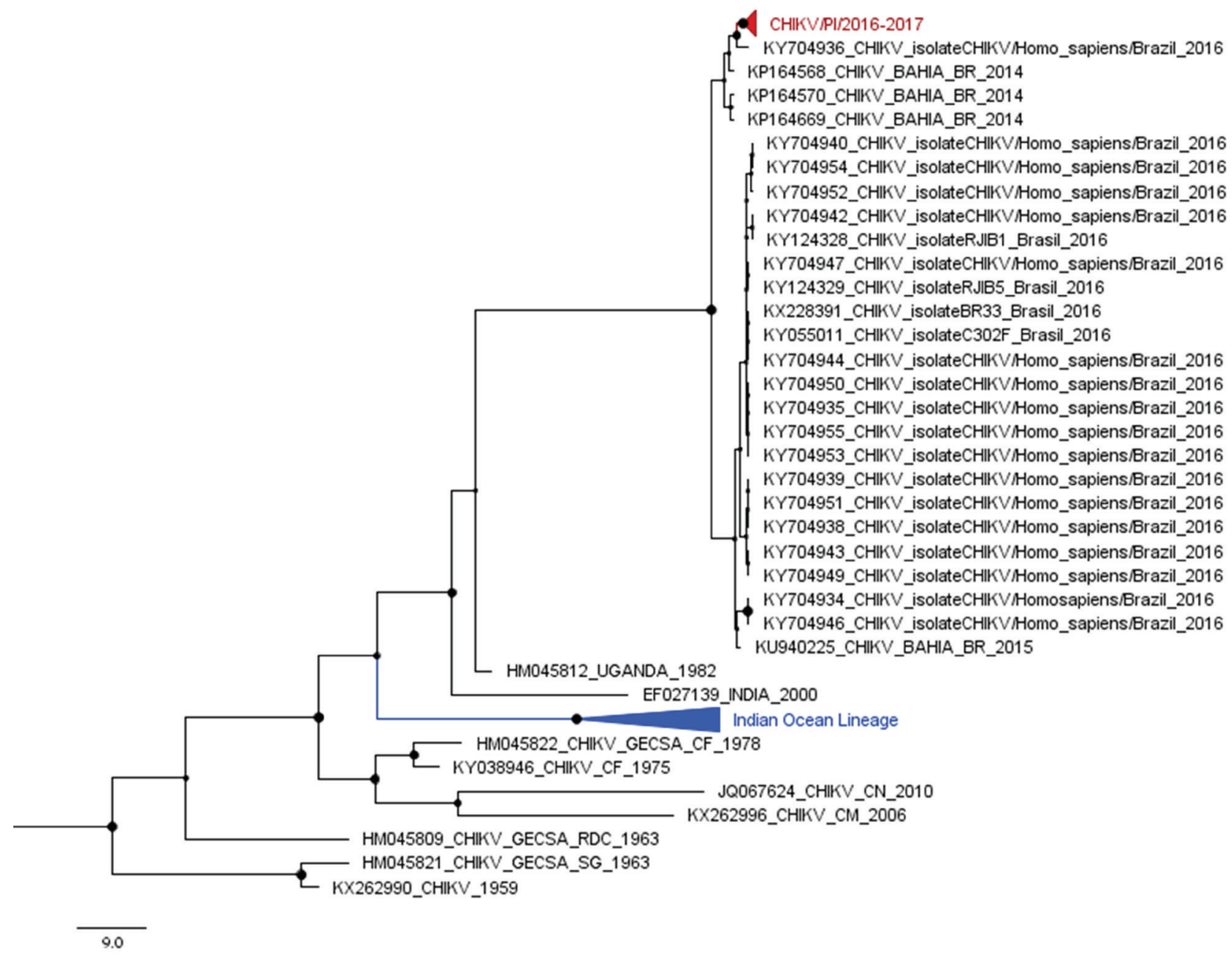

Figure 3 - Bayesian phylogenetic analysis of Chikungunya virus. A subtree of the ECSA genotype, from the maximum clade credibility tree inferred using 88 Chikungunya virus sequences $(328 \mathrm{nt})$ is shown. The posterior probability values are represented by circles drawn in scale in the nodes. Clades containing strains from Piaui (2016/2017) and the Indian Ocean Lineage are shown in red and blue, respectively. Branch lengths are drawn to scale of years. The tree was reconstructed using the nucleotide substitution model GTR with gamma distribution (four categories), under the relaxed molecular clock and the Bayesian skyline demographic model. PI: Piaui. BR: Brazil. GECSA: Genotype East-Central South African. CHIKV: Chikungunya virus. 


\section{DISCUSSION}

In this study, we performed a molecular investigation of CHIKV infection in symptomatic patients in Piaui State, Northeast Brazil, during 2016 and 2017. By using molecular tests, CHIKV infections were confirmed in 33 patients out of 112 tested samples. As the presence of acute symptoms such as fever, arthralgia, myalgia and headache lasting less than 5 days after the onset of the symptoms was a criterion of inclusion, our symptoms data should be carefully considered. However, it is noteworthy to add that one of the CHIKV-positive patients developed encephalitis, the most common neurological complication reported during outbreaks in La Reunion ${ }^{34}$, Guadeloupe and Martinique ${ }^{35}$ islands.

It is difficult to estimate the incidence of neurological symptoms among infected patients, however, encephalopathies are the most common neurological disorders associated with CHIKV infection ${ }^{36}$. On the other hand, symptoms such as fever, arthralgia, headache and myalgia are better described in CHIKV infected patients. These symptoms were the most prevalent in our positive samples, and were also observed in patients from Alagoas $^{33}$ and Sergipe ${ }^{37}$ States, Northeast Brazil.

After the partial nucleotide sequencing of E1 and E2 genes, phylogenetic analysis indicated that the Piaui CHIKV isolates presented in this study were clustered within the ECSA genotype and formed a monophyletic clade with other Brazilian samples from 2014 to 2016. Based on the evolutionary analysis, our extracted viral RNAs share the most common recent ancestor dating from 2015, suggesting the introduction of CHIKV ECSA genotype into Piaui probably in that year. Studies performed in Pernambuco ${ }^{38}$ and Alagoas ${ }^{33}$ States, also located in the Brazilian Northeast region, have suggested that $\mathrm{CHIKV}$ was also introduced in these States in 2015.

Moreover, the interval between the introduction of CHIKV in Piaui in 2015, and the report of its detection made only in 2016 by the surveillance system, demonstrated a silent circulation and maintenance of the virus in the region ${ }^{18,39}$. These data corroborate the finding from Costa $e t \mathrm{al}^{33}$, who estimated the introduction of CHIKV in Alagoas in mid-April 2015, but the virus was detected by the surveillance system a few months later ${ }^{33}$. Furthermore, a recent study on isolates from Rio de Janeiro, Southeast Brazil, has shown that the introduction of CHIKV ECSA genotype in the State may have taken place almost a year after its detection by the surveillance system $^{40}$. Altogether, these data corroborate our finding that CHIKV may have been circulating in Piaui up to a year before its detection.

\section{CONCLUSION}

In conclusion, we provided the first genotype surveillance of CHIKV cases during 2016/2017 in Piaui State, Northeast Brazil. Our study corroborates the circulation of the ECSA genotype in other Brazilian Northeastern States during this period, such as Bahia ${ }^{41}$, Sergipe ${ }^{32}$ and Alagoas ${ }^{33,42}$. Our data also indicate the introduction of CHIKV in Piaui in 2015, and its maintenance up to 2017. Since previous studies have shown a high incidence of chronic symptoms ${ }^{7,8}$, which could have social and economic impacts, more research is needed to evaluate the prevalence and impact of acute and chronic CHIKV infections in the region.

\section{ACKNOWLEDGMENTS}

We would like to thank colleagues from Laboratorio de Biologia de Microrganismos e Plantas - UFPI, and from Laboratorio de Virus - UFMG for their support. We also thank the administrative and laboratory staff from the public health facilities for their support with the samples collection.

\section{AUTHORS' CONTRIBUTIONS}

FDC and GPF conceived and designed the study. IMR, LS, NIOS and BPD carried out experiments and performed phylogenetis analyses. PAA sequenced the PCR fragments. FDC, ELTB and TCCSG collected the patient samples and performed the experiments. JOS, ACTCP and EGK contributed with reagents and materials. FDC, IMR, BPD and GPF analyzed the data and wrote the paper.

\section{FINANCIAL SUPPORT}

This study was supported by grants from Piaui Research Foundation - FAPEPI, Prefeitura Municipal de Parnaiba and from Brazilian National Research Council (CNPq) 456707/2014-0. ELTB, TCCSG, IMR and LS. were supported by graduate fellowships from the Coordination for the Improvement of Higher Education Personnel CAPES. NIOS was supported by a graduate fellowship from CNPq. EGK and BPD are fellows of CNPq. The funding agencies had no role in data collection, data analysis, data interpretation, and writing of this manuscript.

\section{REFERENCES}

1. Tang BL. The cell biology of Chikungunya virus infection. Cell Microbiol. 2012;14:1354-63.

2. Weaver SC, Lecuit M. Chikungunya virus and the global spread of a mosquito-borne disease. N Engl J Med. 2015;372:1231-9. 
3. Nakkhara P, Chongsuvivatwong V, Thammapalo S. Risk factors for symptomatic and asymptomatic chikungunya infection. Trans R Soc Trop Med Hyg. 2013;107:789-96.

4. Queyriaux B, Simon F, Grandadam M, Michel R, Tolou H, Boutin JP. Clinical burden of chikungunya virus infection. Lancet Infect Dis. 2008;8:2-3.

5. Ayu SM, Lai LR, Chan YF, Hatim A, Hairi NN, Ayob A, et al. Seroprevalence survey of Chikungunya virus in Bagan Panchor, Malaysia. Am J Trop Med Hyg. 2010;83:1245-8.

6. Sissoko D, Moendandze A, Malvy D, Giry C, Ezzedine K, Solet $\mathrm{JL}$, et al. Seroprevalence and risk factors of Chikungunya virus infection in Mayotte, Indian Ocean, 2005-2006: a populationbased survey. PLoS One. 2008;3:e3066.

7. Paixão ES, Rodrigues LC, Costa MC, Itaparica M, Barreto F, Gérardin P, et al. Chikungunya chronic disease: a systematic review and meta-analysis. Trans R Soc Trop Med Hyg. 2018;112:301-16.

8. Feldstein LR, Rowhani-Rahbar A, Staples JE, Weaver MR, Halloran ME, Ellis EM. Persistent arthralgia associated with Chikungunya virus outbreak, US Virgin Islands, December 2014-February 2016. Emerg Infect Dis. 2017;23:673-6.

9. Robinson MC. An epidemic of virus disease in Southern Province, Tanganyika Territory, in 1952-53. I. Clinical features. Trans R Soc Trop Med Hyg. 1955;49:28-32.

10. Volk SM, Chen R, Tsetsarkin KA, Adams AP, Garcia TI, Sall AA, et al. Genome-scale phylogenetic analyses of Chikungunya virus reveal independent emergences of recent epidemics and various evolutionary rates. J Virol. 2010;84:6497-504.

11. Sergon K, Njuguna C, Kalani R, Ofula V, Onyango C, Konongoi LS, et al. Seroprevalence of Chikungunya virus (CHIKV) infection on Lamu Island, Kenya, October 2004. Am J Trop Med Hyg. 2008;78:333-7.

12. Renault P, Solet J, Sissoko D, Balleydier E, Larrieu S, Filleul L, et al. A major epidemic of Chikungunya virus infection on Réunion Island, France, 2005-2006. Am J Trop Med Hyg. 2007;77:727-31.

13. Rezza G, Nicoletti L, Angelini R, Romi R, Finarelli AC, Panning $\mathrm{M}$, et al. Infection with Chikungunya virus in Italy: an outbreak in a temperate region. Lancet. 2007;370:1840-6.

14. Leparc-Goffart I, Nougairede A, Cassadou S, Prat C, de Lamballerie X. Chikungunya in the Americas. Lancet. 2014;383:514.

15. Nunes MR, Faria NR, Vasconcelos JM, Golding N, Kraemer MU, Oliveira LF, et al. Emergence and potential for spread of Chikungunya virus in Brazil. BMC Med. 2015;13:102.

16. Teixeira MG, Andrade AM, Costa MC, Castro JS, Oliveira FL, Goes CS, et al. East/Central/South African genotype Chikungunya virus, Brazil, 2014. Emerg Infect Dis. 2015;21:906-8.

17. Brasil. Ministério da Saúde. Secretaria de Vigilância em Saúde. Monitoramento dos casos de dengue, febre de Chikungunya e doença aguda pelo vírus Zika até a Semana Epidemiológica 49 de 2018. Bol Epidemiol. 2018;49:1-14. [cited 2019 May 27]. Available from: http://portalarquivos2.saude.gov.br/images/ pdf/2019/janeiro/02/2018-067.pdf

18. Brasil. Ministério da Saúde. Secretaria de Vigilância em Saúde. Monitoramento dos casos de dengue, febre de Chikungunya e febre pelo vírus Zika até a Semana Epidemiológica 49, 2016. Bol Epidemiol. 2017;47:1-10. [cited 2019 May 27]. Available from: http://portalarquivos2.saude.gov.br/images/pdf/2016/ dezembro/20/2016-033---Dengue-SE49-publicacao.pdf

19. Brasil. Ministério da Saúde. Secretaria de Vigilância em Saúde. Monitoramento dos casos de dengue, febre de Chikungunya e febre pelo vírus Zika até a Semana Epidemiológica 50, 2017. Bol Epidemiol. 2017;48:1-13. [cited 2019 May 27]. Available from: http://portalarquivos2.saude.gov.br/images/pdf/2018/ janeiro/10/2017-046-Publicacao.pdf

20. Kumar CV, Johnson AM, Gopal DV. Molecular characterization of Chikungunya virus from Andhra Pradesh, India \& phylogenetic relationship with Central African isolates. Indian J Med Res. 2007;126:534-40.

21. Porter KR, Tan R, Istary Y, Suharyono W, Sutaryo, Widjaja S, et al. A serological study of Chikungunya virus transmission in Yogyakarta, Indonesia: evidence for the first outbreak since 1982. Southeast Asian J Trop Med Public Health. 2004;35:40815.

22. Kearse M, Moir R, Wilson A, Stones-Havas S, Cheung M, Sturrock S, et al. Geneious Basic: an integrated and extendable desktop software platform for the organization and analysis of sequence data. Bioinformatics. 2012;28:1647-9.

23. Tamura K, Stecher G, Peterson D, Filipski A, Kumar S. MEGA6 : Molecular Evolutionary Genetics Analysis Version 6.0. Mol Biol Evol. 2013;30:2725-9.

24. Posada D. jModelTest: phylogenetic model averaging. Mol Biol Evol. 2008;25:1253-6.

25. Drummond AJ, Suchard MA, Xie D, Rambaut A. Bayesian phylogenetics with BEAUti and the BEAST 1.7. Mol Biol Evol. 2012;29:1969-73.

26. Drummond AJ, Rambaut A. BEAST : Bayesian evolutionary analysis by sampling trees. BMC Evol Biol. 2007;7:214.

27. Baele G, Lemey P, Bedford T, Rambaut A, Suchard MA, Alekseyenko AV. Improving the accuracy of demographic and molecular clock model comparison while accommodating phylogenetic uncertainty. Mol Biol Evol. 2012;29:2157-67.

28. BEAST Developers. Tracer. [cited 2019 Sep 12]. Available from: http://beast.community/tracer

29. BEAST Developers. TreeAnnotator. [cited 2019 Sep 12]. Available from: https://beast.community/treeannotator

30. Rambaut A. FigTree. [cited 2019 Sep 9]. Available from: http://tree.bio.ed.ac.uk/software/figtree/

31. Cunha MS, Cruz NV, Schnellrath LC, Medaglia ML, Casotto ME, Albano RM, et al. Autochthonous transmission of East/ 
Central/South African genotype Chikungunya virus, Brazil. Emerg Infect Dis. 2017;23:1737-9.

32. Costa-da-Silva AL, Ioshino RS, Petersen V, Lima AF, Cunha MP, Wiley MR, et al. First report of naturally infected Aedes aegypti with Chikungunya virus genotype ECSA in the Americas. PLoS Negl Trop Dis. 2017;11:e0005630.

33. Costa AC, Thézé J, Komninakis SC, Sanz-Duro RL, Felinto MR, Moura LC, et al. Spread of Chikungunya virus East/Central/ South African genotype in Northeast Brazil. Emerg Infect Dis. 2017;23:1742-4.

34. Lemant J, Boisson V, Winer A, Thibault L, André H, Tixier F, et al. Serious acute Chikungunya virus infection requiring intensive care during the Reunion Island outbreak in 2005-2006. Crit Care Med. 2008;36:2536-41.

35. Crosby L, Perreau C, Madeux B, Cossic J, Armand C, HerrmannStorke $\mathrm{C}$, et al. Severe manifestations of Chikungunya virus in critically ill patients during the 2013-2014 Caribbean outbreak. Int J Infect Dis. 2016;48:78-80.

36. Mehta R, Gerardin P, Brito CA, Soares CN, Ferreira ML, Solomon T. The neurological complications of Chikungunya virus: a systematic review. Rev Med Virol. 2018;28:e1978.

37. Cunha MP, Santos CA, Lima Neto DF, Schanoski AS, Pour SZ, Passos SD, et al. Outbreak of Chikungunya virus in a vulnerable population of Sergipe, Brazil: a molecular and serological survey. J Clin Virol. 2017;97:44-9.
38. Machado LC, Morais-Sobral MC, Campos TL, Pereira MR, Albuquerque MF, Gilbert C, et al. Genome sequencing reveals coinfection by multiple Chikungunya virus genotypes in a recent outbreak in Brazil. PLoS Negl Trop Dis. 2019; 13:e007332.

39. Brasil. Ministério da Saúde. Secretaria de Vigilância em Saúde. Monitoramento dos casos de dengue, febre de Chikungunya e febre pelo vírus Zika até a Semana Epidemiológica 52, 2015. Bol Epidemiol. 2016;47:1-10. [cited 2019 May 27]. Available from: http://portalarquivos2.saude.gov.br/images/pdf/2016/ janeiro/15/svs2016-be003-dengue-se52.pdf

40. Souza TM, Vieira YR, Delatorre E, Barbosa-Lima G, Luiz RL, Vizzoni A, et al. Emergence of the East-Central-South-African genotype of Chikungunya virus in Brazil and the city of Rio de Janeiro may have occurred years before surveillance detection. Sci Rep. 2019;9:2760.

41. Sardi SI, Somasekar S, Naccache SN, Bandeira AC, Tauro LB, Campos GS, et al. Coinfections of Zika and Chikungunya viruses in Bahia, Brazil, identified by metagenomic nextgeneration sequencing. J Clin Microbiol. 2016;54:2348-53.

42. Tanabe EL, Tanabe IS, Santos EC, Marques JP, Borges AA, Lima MC, et al. Report of East-Central South African Chikungunya virus genotype during the 2016 outbreak in the Alagoas State, Brazil. Rev Inst Med Trop Sao Paulo. 2018;60:e19. 


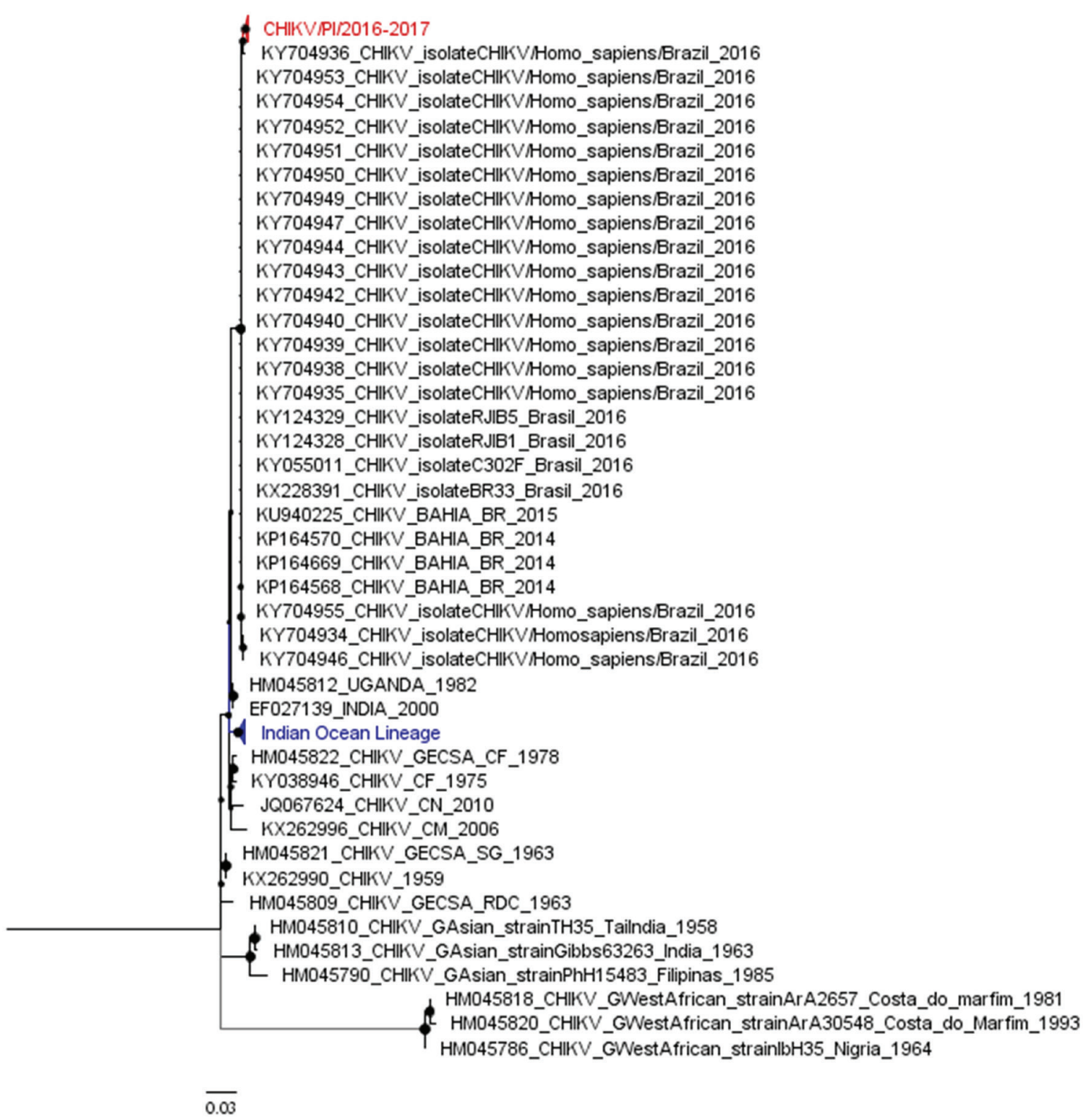

Supplemental Figure 1 - Maximum likelihood analysis of Chikungunya virus. The maximum likelihood tree was inferred using 88 Chikungunya virus sequences (328 nt). The bootstrap values are represented by circles drawn in scale in the nodes. Clades containing strains from Piaui (2016/2017), and Indian Ocean Lineage are shown in red and blue, respectively. Branch lengths are drawn to scale or the number of substitutions per site. The tree was reconstructed using the nucleotide substitution model Kimura2-parametrers with gamma distribution (four categories) (K2+G). PI: Piaui State. GECSA: Genotype East-Central South African. Gwest African: Genotype West African. GAsian: Genotype Asian. CHIKV: Chikungunya virus. 